\section{Protecting the community: Essential workers, nursing homes, and the incarcerated Joshua Freeman, MD}

Originally published in the Medicine and Social Justice blog, https://medicinesocialjustice.blogspot.com/2020/12/protecting-community-essential-workers.html

The COVID-19 pandemic continues, resurging across the US and in many other places. Different strategies have been adopted in different places, with varying degrees of success in slowing the spread of infection and death. This should provide us with information on what works well, and what strategies we should be adopting. For one example, family medicine colleagues in São Paulo, Brazil, report on their experience in nursing homes in the Royal Australian Journal of General Practice. They used public health management techniques including no visitors, rigid use of testing, recommended PPE and isolation, and others, as well as medical management and psychosocial management working with families and patients to help them through this process. They have had only 4 cases in the last 90 days (as of the November publication date), no people in isolation, and a low death rate.

In Arizona, as in the US, case rates and mortality continue to rise. We have more cases than ever, and fewer hospital and ICU beds. The state has chosen to address this issue by lifting restrictions on businesses, opening restaurants, bars, salons and gyms. Based on all evidence from everywhere, this is likely to further increase infections and deaths ("Health chief changes benchmarks so no Arizona business will be shuttered in pandemic".) It was clearly done in response to business owners concerned about their livelihoods and the probability that they will even survive, a real problem for them, and for us, in the horrific

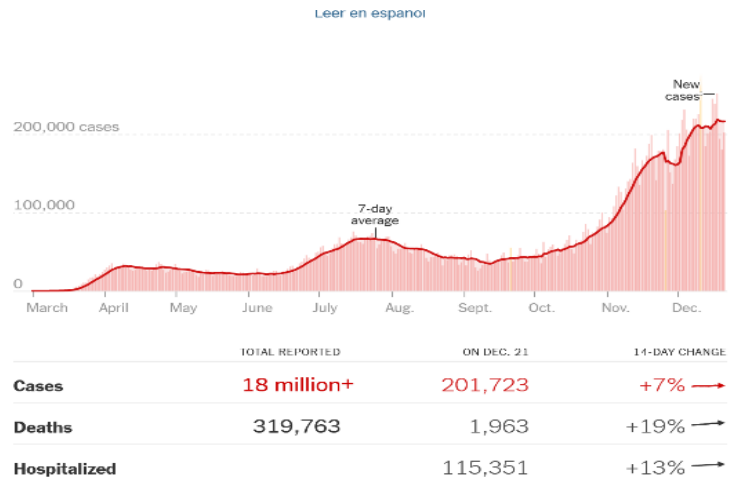

economic downturn that has accompanied the pandemic for most people (for major investors, however, the stock market has done well). Pima County, where Tucson is, has taken a more aggressive and restrictive approach; after more than 320 cases reported among county employees, including the chief health officer, it has furloughed $20 \%$ of the work force for 3 weeks. Obviously, this will be an economic hardship for those people's families.

Thus we have the situation where we know what to do to prevent increased infections and deaths, but have to also address the serious financial impact on regular people who lose their jobs and businesses and incomes. Sadly, efforts to reopen have been almost linearly associated with increased infection rates and deaths. The efforts taken by our Brazilian colleagues were effective in an important and high-risk, but ultimately limited, venue, that of nursing homes. The fact that the increased infection and death rate in our communities will take its greatest toll on the elderly and those with chronic disease, not those whose exposure to others in workplaces, schools, and meetings (although they are also at risk, and not immune) makes it even more complicated. The leadership at the federal level, sometimes inaccurately described as "lack of leadership" when in fact it is actively leading us in entirely the wrong direction, is making things much worse, and creating and exacerbating an incorrect understanding of the disease among many people.

Those who work in high-risk occupations who cannot "phone (or Zoom) it in" but rather have to be present, most often among the lowest paid, those who live in multigenerational and multi-family households, are paying the highest price. These people are not only members of racial and ethnic minority groups, but those groups are far overrepresented in their numbers. A recent article in the New York Times again makes the point that Black and Latinx people are hardest hit, not because of any genetic or biologic reason but because of their social and economic situation resulting from centuries of structural racism. Race, it is clear but requires repeating, is a social, not a biological, construct. The negative impacts on health, income, longevity, education, and everything else is not from "race" but from "racism"; indeed, the only significance of "race" is that it is the basis for racism.

Now there is a vaccine (actually, two, and probably soon three, vaccines) and administration of them is rolling out, especially in the wealthy countries that have acquired most of the doses (of course, in the US the Trump administration jeopardized this by passing on an opportunity to acquire 
more doses of the Pfizer vaccine, and this was certainly not to help out the poor parts of the world!) The debate now moves to who should get it first and in what order. In most places in the US, priority is going to health care workers and nursing home patients, which makes sense. They are, respectively, the most likely to contract and transmit the infection and the most likely to die from it. And then? Who? Those with the highest risk or those with the best connections? In many hospitals we hear reports of the $\mathrm{C}$-suite executives (the "front office") being at the front of the line for vaccine, despite the fact that they do no health care. Nice of them to want to "model" behavior, but the vaccine should go first to those who see patients. The priority should be those who not only interact with the public, but who cannot do their jobs if they don't actually show up for work, and among those, people who would be the worst off if they lost their jobs (and those who have already been laid off but might be able to come back and begin working again). The last would be those who can continue to work from home, or are retired without major health risks, and can continue to isolate themselves.

Another major group that is finally getting so media attention, even if it is unlikely to get much vaccine, is the incarcerated population. The AP reports that " 1 in 5 prisoners in the US has had COVID-19, 1,700 have died”. This could be predicted; it is a group crowded together, unable to isolate, often with pre-existing conditions, and essentially without agency - they have to do what they are told. There are, broadly, two reasons for immunizing them. The first is human - they are human, and they are at very high risk, and they are already being punished; they should not be further punished by getting this disease. The second is practical; prisoners are not, actually, entirely separate from the rest of the population. In addition to guards and others who move between the inside and the outside, many prisoners are released; this is most especially true for jails, where the length of stay is short (usually awaiting a court appearance for those who cannot post bond), and thus is really part of the community from which inmates come and go back to. Nathaniel Lash makes this case convincingly in the New York Times Sunday Review, "The coronavirus has found a safe harbor". For example,

Cook County Jail was the site of the largest detected outbreak in the country early in the pandemic. In recent weeks, it has exceeded that - there were 340 active cases among inmates on Dec. 16. The population, meanwhile, has returned to levels typical before the pandemic, about 5,500 people.
We should have fewer people in jail. It is outrageous that people are incarcerated because they cannot pay bond, overt discrimination against the poor, and cannot afford to support the very politically powerful bail-bond industry. This was true before COVID, and is more true now. “There's no question with a new peak in infections that we have to be decarcerating now," said Dr. Emily Wang, the director of Yale School of Medicine’s Health Justice Lab. "If we don't have larger-scale decarceration efforts, we won't control Covid." The answer is bail reform that corrects these inequities - vicious inequities with frequently fatal outcomes. But the opposition continues to cloak itself in the mantle of morality rather than greed, public safety rather than racism. "We're seeing the extent of the opposition to bail reform: They so strongly oppose it they will do it in the face of a pandemic," said Andre Segura, legal director for the American Civil Liberties Union in Texas.'

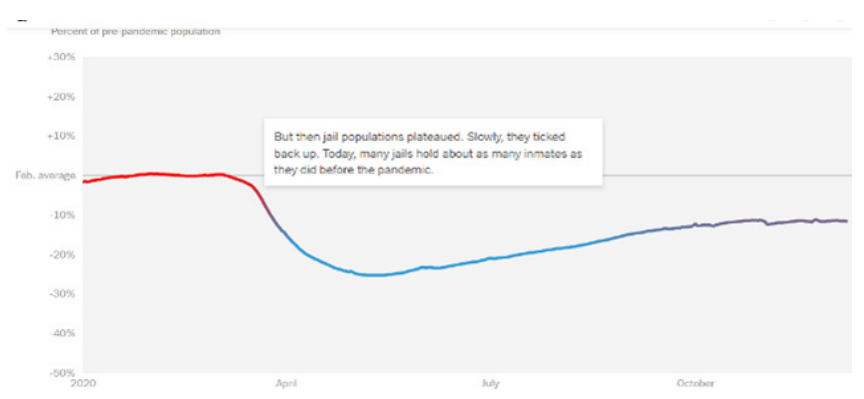

The US incarcerates more people than anywhere in the world, a lot for relatively minor drug offenses. This does not prevent crime, especially violent crime, and it continues to rise even as crime rates decrease. In 2020 it is out of control, it is inhumane, and it is a significant cause of the spread of COVID.

We need to get the vaccine out there soon, especially to those at highest risk of both dying and transmitting it to others. Clearly, the incarcerated population must be included.

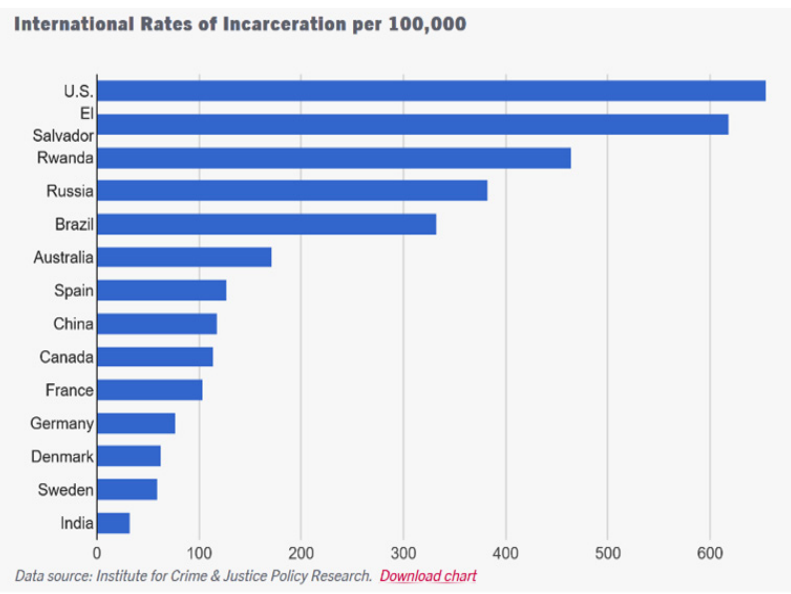

